\title{
Microbial Recovery of Gold Metal From Untreated and Pretreated Electronic Wastes by Wild and Mutated Cyanogenic Bacillus megaterium
}

\author{
Alshehri A.N.Z. \\ Department of Biology, University college in Al-Jummum, Umm Al-Qura University, Makkah, 21955, Saudi Arabia \\ *Corresponding author: anshehri@uqu.edu.sa
}

\begin{abstract}
Technology of biorecovery by Bacillus megaterium to obtain gold as a complex of gold-cyanide from electronic waste material (EWM) was done. The bacteria were subjected to pretreatment and mutation. The exist metals in solution were dissolved via the pretreatment, that way, contest for the cyanide ion from other metals was reduced. The bacteria were subjected to mutation to be able grow at $\mathrm{pH} 9,9.5$ and 10 , where the $\mathrm{pKa}$ of $\mathrm{HCN}$ is 9.3, thereby, the cyanide ion concentration available for bioleaching was increased by alkaline $\mathrm{pH}$. The new mutated bacteria from the pretreated EWM at $0.5 \%$ pulp density obtained gold of 17,25 and $21 \%$ at $\mathrm{pH} 9,9.5$ and 10 , respectively. Whereas the old unmutated bacteria that grow at $\mathrm{pH} 7$, recovered $11 \%$. The outcomes demonstrated that effectiveness of the mutated alkaline bacteria (B. megaterium) in gold biorecovery was more than normal physiological ( $\mathrm{pH} 7)$.
\end{abstract}

Keywords: gold metal, bioleaching, electronic waste, mutation, cyanogenic, Bacillus megaterium

Cite This Article: Alshehri A.N.Z., "Microbial Recovery of Gold Metal From Untreated and Pretreated Electronic Wastes by Wild and Mutated Cyanogenic Bacillus megaterium." American Journal of Microbiological Research, vol. 6, no. 1 (2018): 14-21. doi: 10.12691/ajmr-6-1-3.

\section{Introduction}

Contamination of the environment with electronic waste material (EWM) increased recently as result increasing of throwing of electronic devices [1]. The increasing of worldwide demand on electronic devices, and the shorter lifecycles of these goods caused the significant increase in EWM. For example, in computers the lifespan of the processor was dropped from 6 years in 1997 to 2 years in 2005 [2]. The lifespan of mobile phones about 2 years only [3]. Therefore many of hazardous wastes and precious metals, as mercury, cadmium, lead, gold and silver become environmental contaminants, when millions of electronic devices around the world disposal to environment yearly. Around 3.20 million tons of EWM was recorded recently by Environmental Protection Agency in U.S alone, as well as EWM has been specified as major component of solid municipal waste. $82 \%$ of EWM was incinerated or landfilled, just about $18 \%$ was recycled [4]. Some of challenges are encountering landfilling as lack of adequate landfill area, in addition the contamination which has been occurred by leaching of heavy metals into the environment through groundwater, consequently the decontamination is necessary, as well another factor make recycling of EWM worthy it is the recovery of precious metals. Per ton the electronic waste material (EWM) has around 10-10,000 g gold $[5,6]$ and it is significantly higher than the natural gold ores which has around $0.5-13.5$ g gold per ton [6,7], therefore it an applicable alternative and more economic source of gold compared to natural ores. Thereby the demand for primary mineral resources could be reduced [8] For facing increasing gold demand it is necessary to discover new alternative sources of gold such as EWM. Biorecovery by leaching for the extraction of minerals from their ores is process an hydrometallurgical. It is a clean eco-friendly technology and affordable with minimum operating cost and energy consumption, compared to conventional processes $[5,8,9]$.

Bacillus megaterium which was used for biorecovery of gold from EWM in the present work has ability to produce hydrogen cyanide via secondary metabolite, this production occurs for a short period at the early stationary phase, constructing cyanide ion $(\mathrm{CN}-)$ and the non-dissociated form of hydrocyanic acid ( $\mathrm{HCN})$. At the early stationary phase when $\mathrm{pH}$ was 7.0 the cyanide was in form of hydrogen cyanide ( $\mathrm{pKa} 9.3$ ). By progress and at the late stationary and death phase the cyanide has been detoxified by $B$. megaterium via converting it to $\beta$-cyanoalanine [10]. Cyanogenic bacteria like B. megaterium able overall constructing soluble cyanide compounds from from metal-containing solids such as electronic waste material [11]. Elsner's equation (1) elucidate the process of gold cyanidation which mean formation of gold cyanide complex in atmosphere of oxygen [10].

$$
\begin{aligned}
& 4 \mathrm{Au}+8 \mathrm{NaCN}+\mathrm{O}_{2}+2 \mathrm{H}_{2} \mathrm{O} \\
& \rightarrow 4 \mathrm{Na}\left[\mathrm{Au}(\mathrm{CN})_{2}\right]+4 \mathrm{NaOH}
\end{aligned}
$$

Bacteria which have cyanogenic activity concentrate metals like gold under alkaline conditions, while acidophilic 
bacteria were used in biorecovery of the metals solid waste [12]. The alkaline condition and the pKa of $\mathrm{HCN}$ is 9.3 made the gold dissolution process increases the total cyanide ions available for biorecovery. Growth of bacteria under alkaline condition is the major challenge in this process.

The present study was devoted to improve the biorecovery of gold from electronic waste material using $B$. megaterium. The parameters that will be examined in this work are representative in influence of pretreatment of EWM to minimize the competition for cyanide ion from another metals principally copper present in EWM, influence of pulp densities of EWM on gold bioleaching, and applying mutation of the bacteria to be able grow under alkaline conditions to maximize the concentration of cyanide ions available for gold bioleaching.

\section{Materials and Methods}

\subsection{Microorganism}

B. megaterium was obtained from Braunschweig, a German microorganism collection. Activated culture (1\% $\mathrm{v} / \mathrm{v}$ ) was used to inoculate a $100 \mathrm{ml}$ of nutrient broth medium (NBM), comprising g/L of deionized water: yeast extract (2), peptone (5), sodium chloride (5) and meat extract (1). Incubation was done on a rotary shaker at a temperature of $30^{\circ} \mathrm{C}$ and rotation speed of $170 \mathrm{rpm}$ for 20-24 hours until the bacteria reached an early stationary phase characterized by maximum cell density and cyanide production. The bacterial stocks were maintained at $-10^{\circ} \mathrm{C}$ after supplemented them with $30 \%$ of glycerol.

\subsection{Mutation Experiments}

The wild $B$. megaterium was subjected to N-Nitroso N-ethyl urea (ENU) $(100 \mathrm{mM})$ as a mutagen factor. The selected $\mathrm{pH}$ values were $9,9.5$, and 10 , respectively. The mutations were introduced randomly across the genome, which could increase the likelihood of targeting that part of the genome which controls growth rate and $\mathrm{pH}$, as this could permit selecting cells capable of growing in alkaline media.

\subsection{Electronic Waste}

Electronic Waste Material (EWM), mostly comprising of printed circuit boards, was obtained from Holoul Electronic Recycling Treatment Co. (Jeddah-Saudi Arabia). Particles less than $100 \mu \mathrm{m}$ of EWM in the form of grey dust were obtained by shredding and applying other mechanical processes for separation while recycling EWM.

\subsection{Pretreatment Method}

Copper was removed from the EWM using nitric acid by adding $30 \mathrm{~mL}$ of $6 \mathrm{M}$ nitric acid to $10 \mathrm{~g}$ of EWM $(45-75 \mu \mathrm{m})$ in an Erlenmeyer flask $(250 \mathrm{ml})$ at room temperature [13] and shaking the mixture for 2 hours. This was necessary because the presence of nitric acid interferes in the formation of cyanide-gold ion complex. The EWM was added to the nitric acid incrementally in order to minimize frothing as a result of nitric oxide gas being produced. The mixture was then centrifuged for 10 minutes at $5000 \mathrm{rpm}$. Leachate $(5 \mathrm{ml})$ was extracted for metallic analysis using an Inductively Coupled Plasma-Mass Spectrometer (Agilent 7500a: ICP-MS). The remainder supernatant was discarded, and deionized water was used to wash the residue before re-centrifuging. This centrifugation cycle was repeated until there were no longer any visible traces of blue-green copper nitrate. The pretreated EWM pellet was then removed, left to dry, and finally weighed relative to constant mass.

\subsection{Acid Digestion}

The procedure of Yamane et al. [14] was followed in digesting the EWM samples. $1.0 \mathrm{~g}$ of samples were added in Erlenmeyer $(250 \mathrm{ml})$ flasks and digested with aqua regia $(40 \mathrm{ml})$. Prior to centrifugation, the mixture was left to stand for 24 hours. Centrifugation took place for 15 minutes at $5000 \mathrm{rpm}$, and a temperature of $4^{\circ} \mathrm{C}$ was maintained for the supernatant sample. The mass of the solubilized metal was determined by weighing after drying the residue, and ICP-MS was used to analyze the metal concentrations of acid digested and bioleached samples.

\subsection{Scanning Electron Microscopy}

The morphology of the EWM was observed before and after pretreatment using Scanning Electron Microscopy (SEM, JSM-5410LV, JEOL Ltd, Japan). Dried samples of EWM were loaded using carbon tape coated with platinum particles $(10 \mu \mathrm{m})$ onto the copper stubs. An auto fine coater (JEOL JFC-1300) was used under vacuum for this purpose for precisely 1.0 minute at $40 \mathrm{~mA}$. Analysis was then conducted of the original, pretreated and bioleached EWM using Energy Dispersive X-ray Spectroscopy (EDX).

\subsection{Optical Density}

A UV-VIS spectrometer (Metash UV-9000, China) was used to measure the optical densities of bacterial samples at $600 \mathrm{~nm}$. Absorbance within the linear range was ensured by diluting the samples accordingly.

\subsection{Free Cyanide Analysis}

A cyanide electrode (Thermoscientific Orion) connected to an Ion Selective Electrode meter was used to measure the presence of free cyanide in the samples. A six-point calibration was undertaken weekly at $0,0.5,1.5,10$, and 25 ppm.

\subsection{Bioleaching Studies}

EWM bioleaching was conducted in Erlenmeyer flasks (250 ml) containing NBM (100 ml), and at different levels of pulp densities $(0.5,1.0,2.0$ and $4.0 \% \mathrm{w} / \mathrm{v})$. The presence of toxic EWM in a single-step approach causes inhibition of bacterial growth thus the cyanide production is stop, consequently higher gold recovery was obtained by applying two-step bioleaching instead $[15,16]$. The bacteria were cultured on NBM, in an incubator-shaker at $170 \mathrm{rpm}$ and $30^{\circ} \mathrm{C}$ under the path of two-step bioleaching. 
When the cultures had attained significant cell density, and bacterial cyanide production had reached its peak during the early stationary phase, the sterilized EWM was then added to the bacterial cultures. Samples after EWM addition were collected on a daily basis over a period of eight days, filtered and analyzed for their $\mathrm{pH}$ value, heavy metal concentration, particularly gold and copper, and free cyanide concentration.

\section{Results and Discussion}

\subsection{EWM Elemental Composition}

Table 1 presents data of the metal composition of the untreated EWM after acid digestion and the pretreated EWM. The metal ion concentration following acid digestion was used in calculating the percentage of recovery in bioleaching. The EWM mass comprised of metals (32\%), refractory oxides, ceramics and plastics. Similar results were reported in previous studies $[1,17,18,19,20,21]$. Untreated EWM contained mostly copper, base metals such as zinc, iron, lead and aluminium in significant proportions, and in lower concentration, gold, silver and other metals. The metallic composition was thus characterized by heterogeneity, which may be attributed to the origin of the EWM from various sources. Notably, the gold content was higher than found in most other studies $[5,19,20,21,22,23]$, but comparable to that found in Hagelüken and Greinerstraat [24]. The presence of high concentration of copper-cyanide complexes interfere with gold cyanidation [25]. Stable complexes with cyanide are also formed by other metals including iron, zinc, silver and nickel $[11,26,27]$. The EWM was therefore treated with nitric acid in order to dissolve and extract the copper and other metals for enhancing gold cyanidation in further bioleaching. Almost $80 \%$ of the copper was removed as a result of the acid digestion pretreatment.

\subsection{EWM Morphology}

The EWM was shown to be heterogeneous from the SEM micrographs of untreated and pretreated EWM (Figure 1 A \& B). The particles had varying shapes, sizes and textures, mostly spherical or rod-like, and with flakes and fine crystals on their surfaces. Before treating with nitric acid, the EWM appeared to be smoother and finer in texture (Figure 1A). Following the treatment, the EWM surfaces showed signs of erosion thereby making more crevices exposed from chemical leaching (Figure 1B). Conducting of analysis of the original pretreated and bioleached EWM was carried out by Energy dispersive X-ray Spectroscopy (EDX) (Figure 2 A-C). The results revealed a large proportion of silicon in untreated and pretreated EWM, as commonly used in electronic products, and an increased surface gold to copper ratio after pretreatment with most metallic particles removed from the bioleached EWM surface.

Table 1. Elemental composition of untreated and pretreated EWM

\begin{tabular}{cccc}
\hline Metals & Untreated EWM $(\mathrm{mg} / \mathrm{g})$ & Pretreated EWM $(\mathrm{mg} / \mathrm{g})$ & Removed With pretreatment $(\%)$ \\
\hline $\mathrm{Cu}$ & 156.40 & 36.40 & 79.8 \\
$\mathrm{Al}$ & 48.20 & 15.00 & 69.5 \\
$\mathrm{Fe}$ & 32.45 & 11.00 & 71.3 \\
$\mathrm{~Pb}$ & 29.00 & 10.00 & 66.4 \\
$\mathrm{Sn}$ & 17.60 & 2.000 & 88.6 \\
$\mathrm{Ni}$ & 15.00 & 5.000 & 62.5 \\
$\mathrm{Zn}$ & 12.60 & 6.200 & 55.2 \\
$\mathrm{Ag}$ & 0.56 & 0.200 & 64.3 \\
$\mathrm{Au}$ & 0.28 & 0.240 & 14.3 \\
$\mathrm{Total}$ & 340.89 & 86.04 & \\
\hline
\end{tabular}

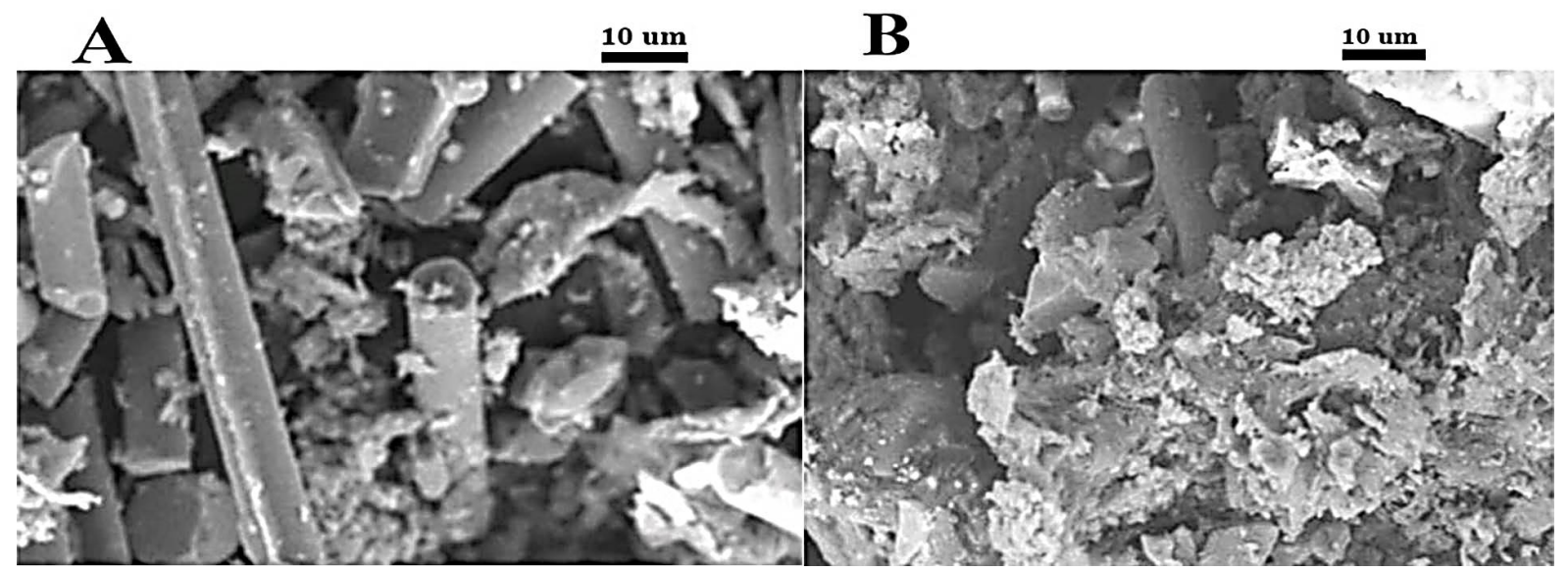

Figure 1. SEM images of (A) original untreated EWM and (B) pretreated EWM at 1000X magnification 


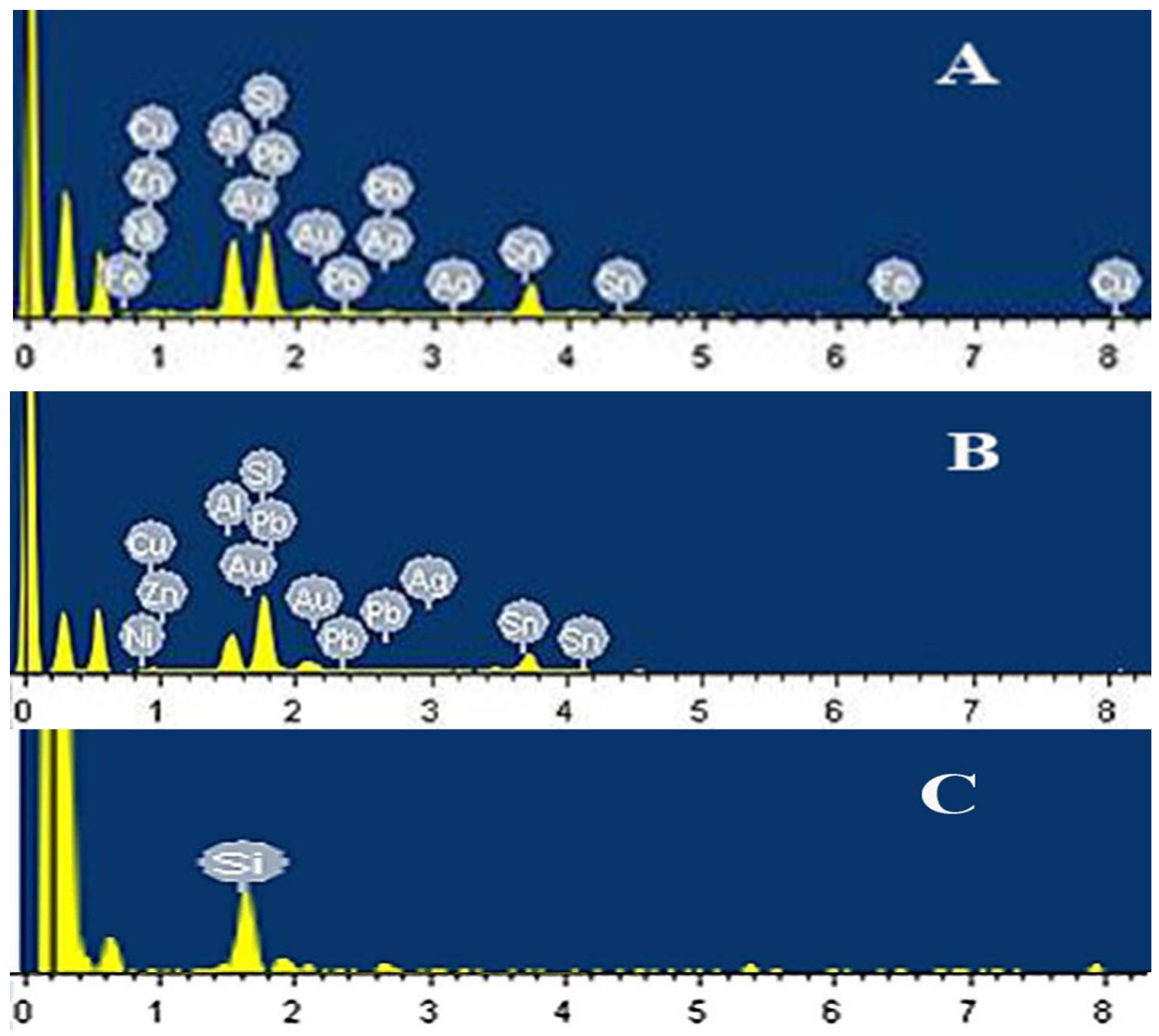

Figure 2. EDX spectra of (A) original untreated EWM, (B) pretreated EWM and (C) Bioleached EWM

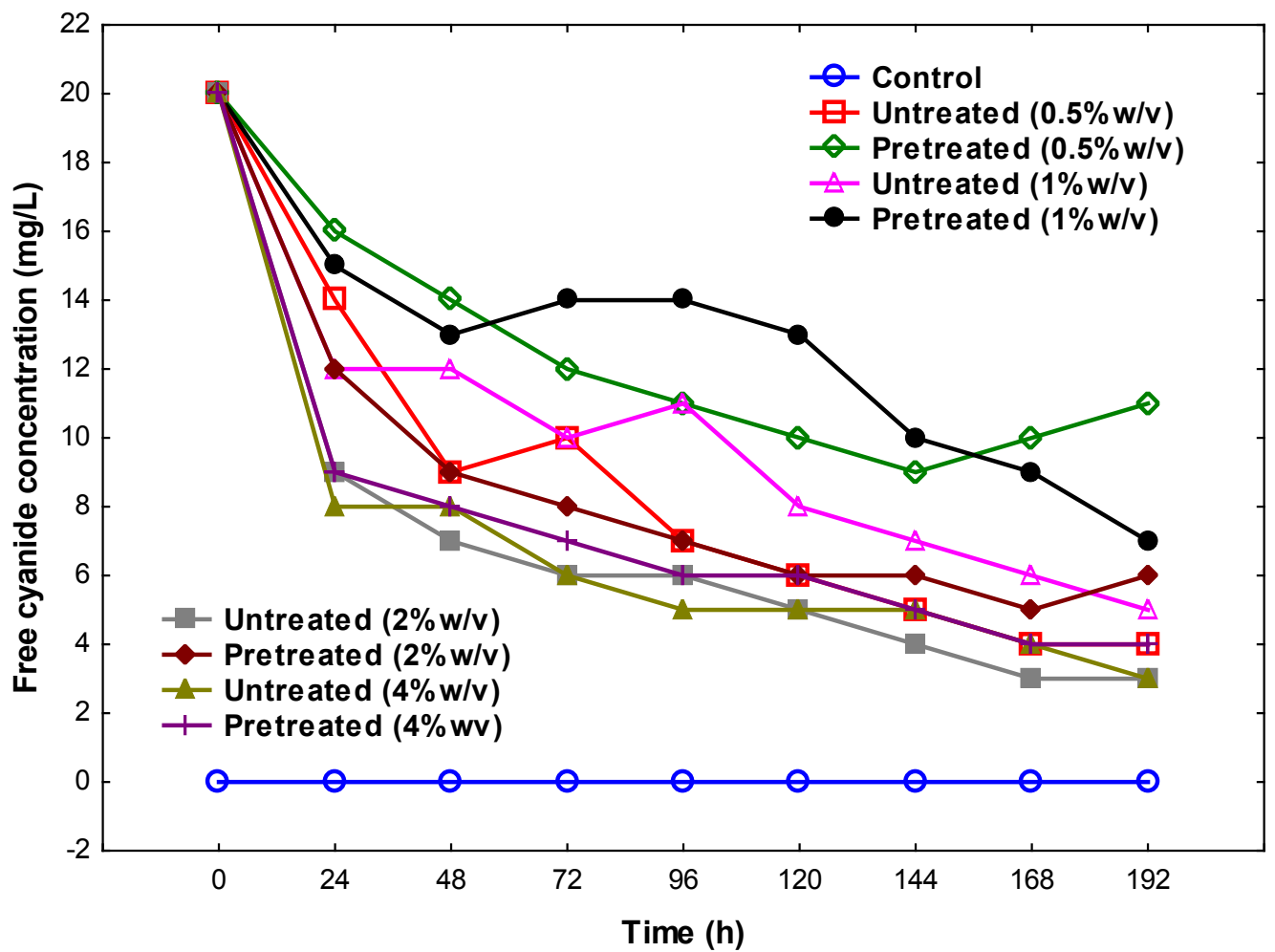

Figure 3. Free cyanide concentration in bioleaching of untreated and pretreated EWM at $0.5 \%, 1 \%, 2 \%$ and $4 \% \mathrm{w} / \mathrm{v}$ pulp density 


\subsection{Two-step Bioleaching of Untreated and Pretreated EWM with Wild Strain}

\subsubsection{Free Cyanide Concentration Profile}

Figure 3 shows free cyanide concentrations in bioleaching cultures of the wild strain for untreated EWM and pretreated EWM at pulp densities between $0.5 \%$ and $4 \%$ $(w / v)$. Cyanide was produced by the cells towards the stationary phase and simultaneously consumed by conversion to $\beta$-cyanoalanine [10]. The data points in the Figure 3 thus show the net cyanide production and outcome of consumption and gold complexation. The concentration of free cyanide was observed to be maximum on Day 0 in the early stationary phase of adding EWM to the bacterial culture. The concentration of free cyanide decreased over time while bioleaching at all pulp densities for both untreated and pretreated EWM. The decrease was sharper at higher pulp densities, possibly due to more free cyanide being consumed by the metals with greater concentrations and increasing pulp densities. During two-step bioleaching, no cyanide was detected in all instances in uninoculated controls. Relative to untreated EWM, higher free cyanide concentration resulted from bioleaching with pretreated EWM. This could be due to inhibition of cyanide production with untreated EWM as a result of higher metal concentration, as the consumption and complexation of cyanide with gold may cause net uncomplexed cyanide concentration to decrease over time without cyanide production by the bacteria. Secondly, it could be due to higher cyanide complexation with metals with untreated EWM given the higher concentration of metals relative to pretreated EWM, which reduces the net concentration of free cyanide. The difference is small between free cyanide concentration at high pulp density in the bioleaching of untreated EWM and pretreated EWM, as EWM toxicity affects cyanide production. That is, reduced cyanide production is the result of reduced concentration of viable cells.

\subsubsection{Gold and Copper Bioleaching Profiles}

Gold leaching by $B$. megaterium at different pulp densities with both untreated EWM and pretreated EWM is shown in Figure 4. Recovery of gold was higher for bioleaching with pretreated EWM at all pulp densities relative to untreated EWM. This result was as expected given the removal of substantial amounts of copper and other metals that also compete with gold in the formation of cyanide-complex. Relative to gold, preferential dissolution of copper could be due to high copper concentration which consumes free cyanide that would otherwise have been consumed by gold cyanide complexation [25]. Notably, gold $\left(\mathrm{E}^{0}{ }_{\mathrm{Au} 3+/ \mathrm{Au}}: 1: 52 \mathrm{~V}\right)$ is nobler than copper $\left(\mathrm{E}_{\mathrm{Cu} 2+/ \mathrm{Cu}}^{0}\right.$ : $0.34 \mathrm{~V}$ ) [28]. Gold could not be detected in uninoculated control during the whole period of bioleaching. This result suggests the production of cyanide by the bacteria was the sole lixiviant involved in the leaching of gold. The high recovery of copper from pretreated EWM relative to untreated EWM after bioleaching for 192 hours is shown in Figure 5. The figures indicate a general decrease in recovery of gold and copper proportions in line with increase in pulp density. As in gold leaching, the recovery of copper from untreated EWM by bioleaching is shown to be lower at all pulp densities relative to pretreated EWM by bioleaching over the same pulp densities. A difference however, is that cyanide is not the only lixiviant for dissolving copper unlike the case with gold leaching. Reagents in the NBM may have leached copper from the EWM in different forms to cyanide-based complex, as evident by the recovery of copper in the uninoculated controls (Figure 5). Copper leaching has been early reported in NBM by Brandl et al. [15]. Pretreated EWM was used for comparing gold bioleaching efficiency between wild and mutated strains with the capability of growth in the alkaline range under $\mathrm{pH}$ on the basis of higher recovery of gold and copper with wild strains for pretreated EWM at pulp density of $0.5 \%$.

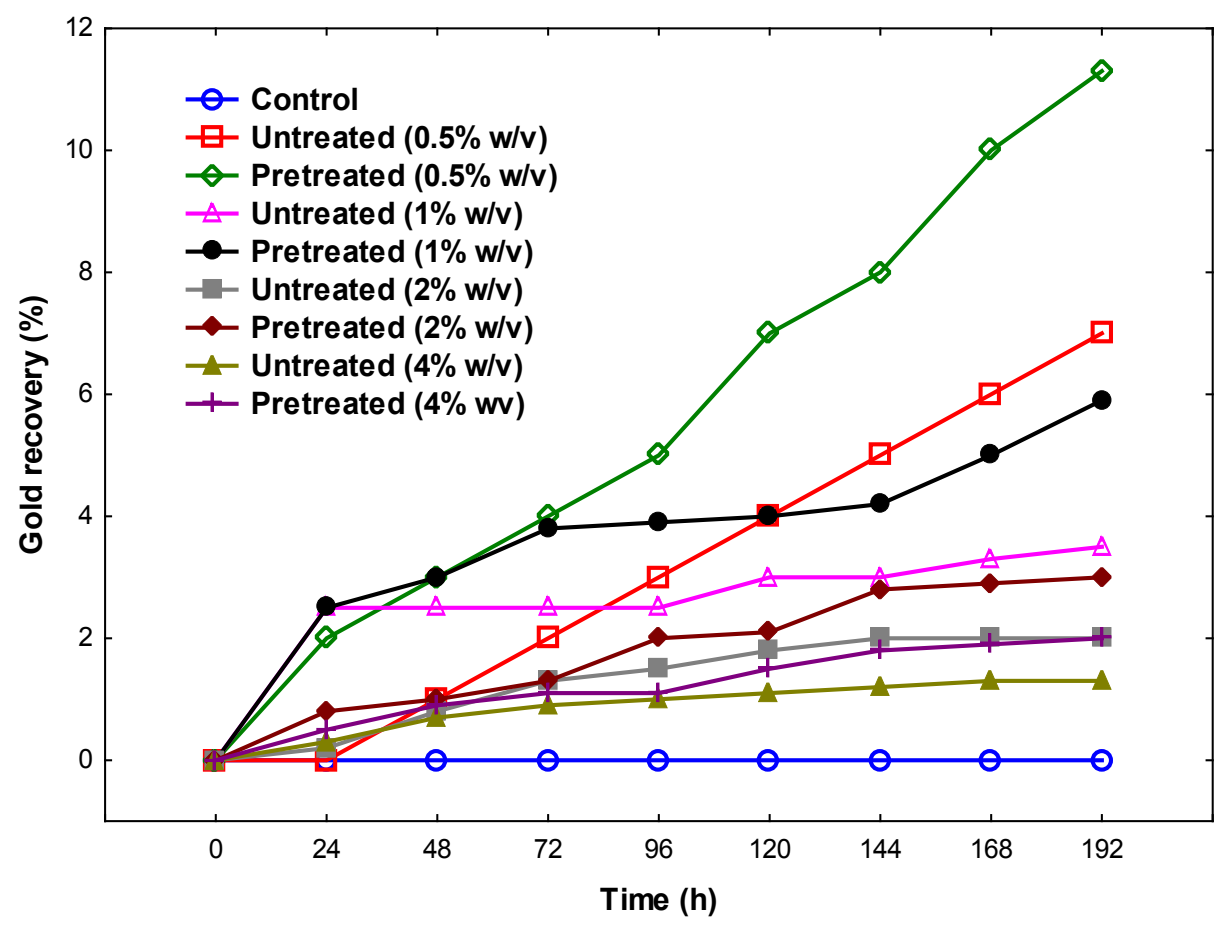

Figure 4. Gold recovery in bioleaching of untreated and pretreated EWM at $0.5 \%, 1 \%, 2 \%$ and $4 \%$ w/v pulp density 


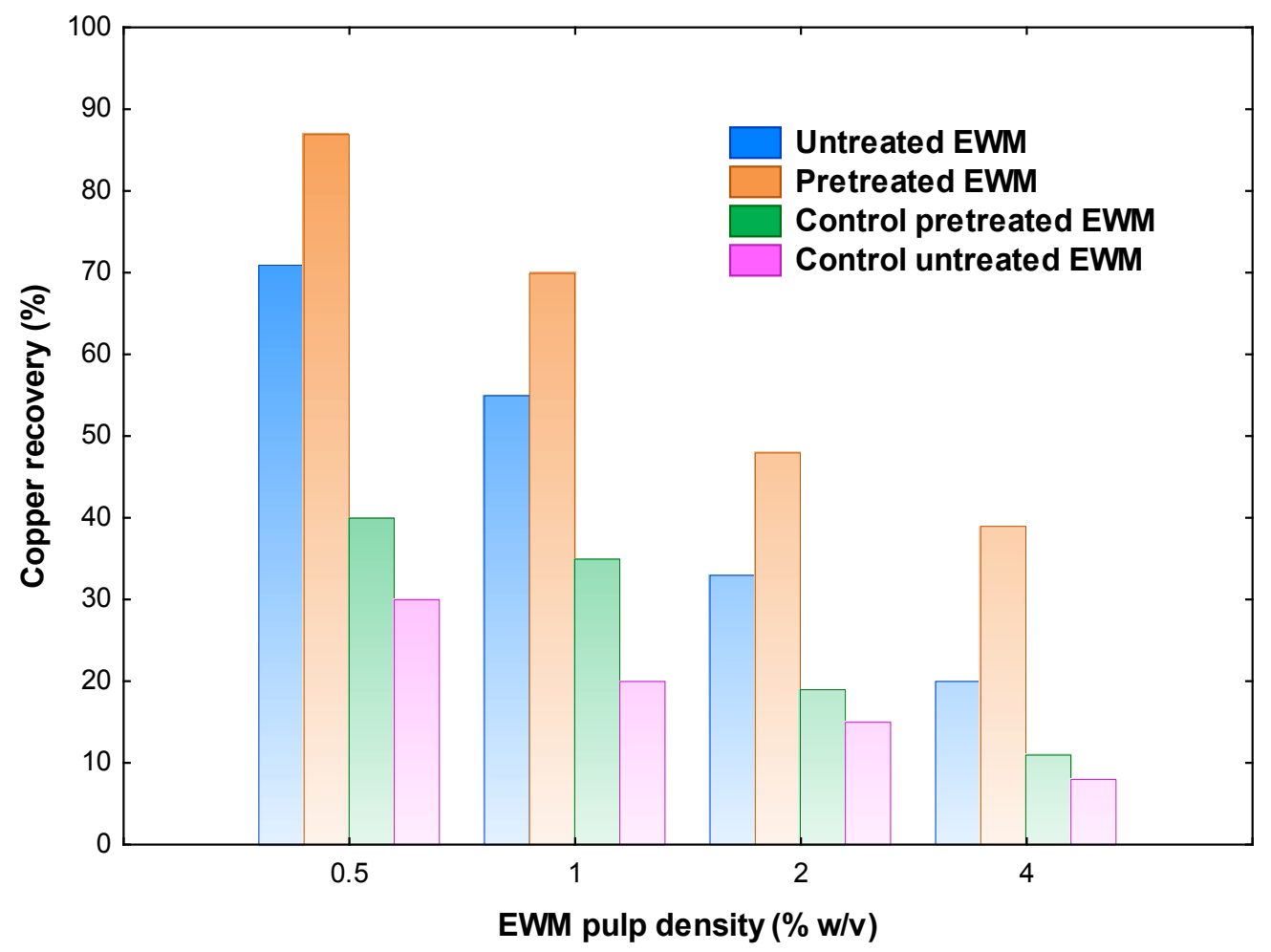

Figure 5. Copper recovery from untreated and pretreated EWM by wild B. megaterium at different pulp densities

\subsection{Growth of Wild and Mutated Strains of B. megaterium}

Growth profiles of the wild mutated and strain bacteria are shown in Figure 6. A higher mutational growth of $B$. megaterium is exhibited at $\mathrm{pH} 9$ and $\mathrm{pH} 9.5$ relative to unmutated strains at the same $\mathrm{pH}$ levels. A $\mathrm{pH}$ of 10 inhibits growth of the wild strain in the absence of mutation. With mutation, growth at $\mathrm{pH} 10$ was also exhibited by the wild strain, but at a lower growth rate relative to the wild strain at physiological $\mathrm{pH}$, and growth of mutated bacteria at $\mathrm{pH} 9$ and $\mathrm{pH} 9.5$.

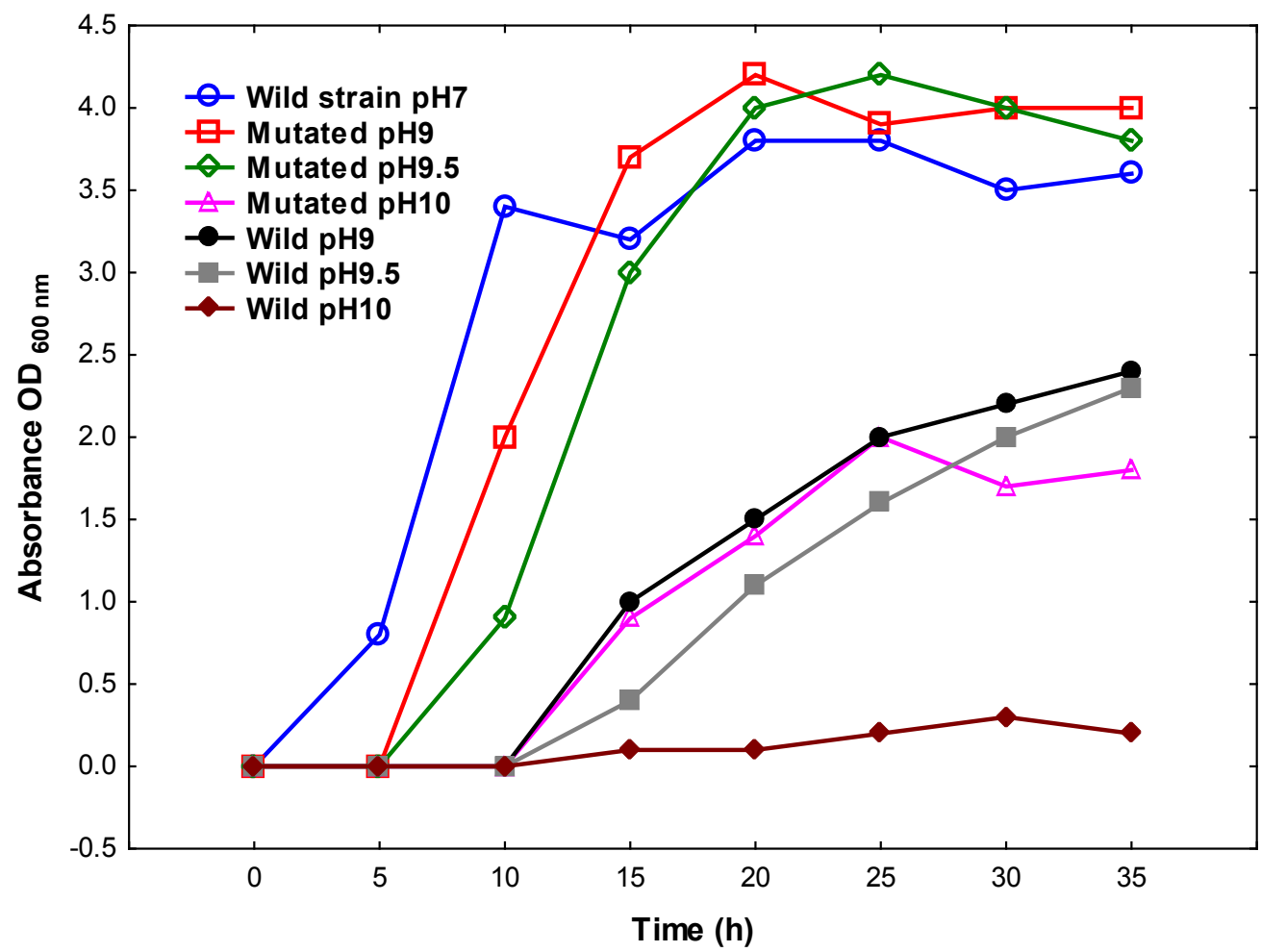

Figure 6. Growth curves of wild and mutated strains of B. megaterium at different $\mathrm{pH}$ and at $30^{\circ} \mathrm{C}$ 


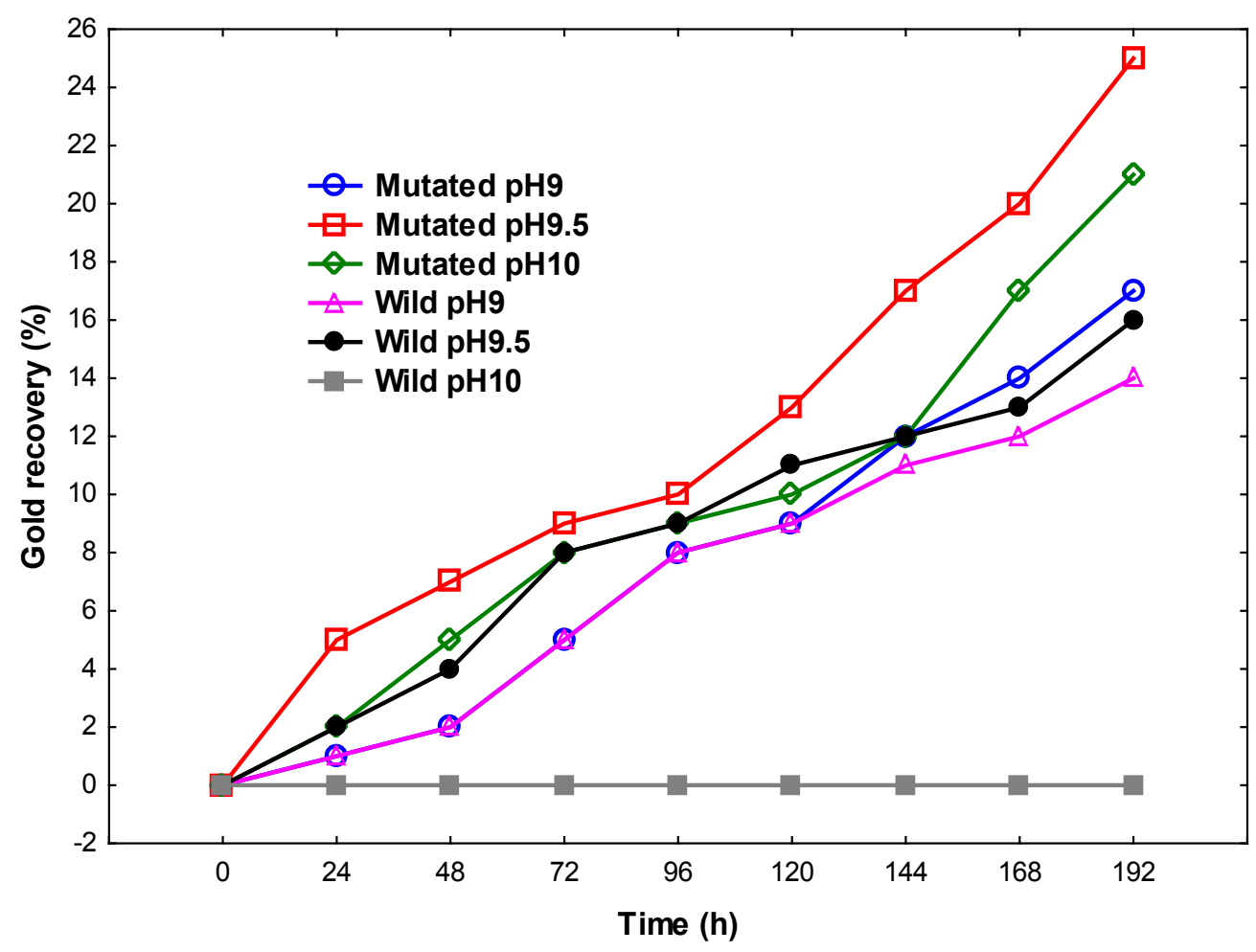

Figure 7. Comparison of gold recovery from pretreated EWM at $0.5 \%$ pulp density, using the wild and mutated strains of $B$. megaterium

\subsection{Pretreated EWM Subjected to Two-step Bioleaching with Mutated $B$. megaterium at Pulp Density of $0.5 \%$}

The recovery of gold from EWM at pulp density of $0.5 \%$ were compared for both wild and mutated strains (Figure 7). The highest gold recovery (25\%) was achieved when B. megaterium mutated at $\mathrm{pH}$ of 9.5 after which $21 \%$ of the bacteria mutated at $\mathrm{pH} 10$, and $17 \%$ at $\mathrm{pH} 9$. Cyanide availability for bioleaching of gold is subject to two important factors. Firstly, bacterial growth and cyanide production reach peak levels during the initial physiological range of $\mathrm{pH} 7-8$ [29]. However, cyanide is likely to be lost at this $\mathrm{pH}$ due to volatilization given that the gaseous hydrogen cyanide has a $\mathrm{pKa}$ of 9.3 , the remaining cyanide concentration in the solution being highly dependent on the $\mathrm{pH}$ value [30], and that a high $\mathrm{pH}$ value is more favorable. Bacterial mutation in an alkaline condition allows for growth and production of cyanide, which simultaneously increases cyanide ion availability to improve the recovery potential of gold. At $\mathrm{pH} 10$, dissociation tends to be greater, but mutated growth of $B$. megaterium at $\mathrm{pH} 10$ exhibited lower recovery of gold at $21 \%$ relative to the recovery of $25 \%$ at $\mathrm{pH}$ 9.5. This growth is significantly lower in comparison to others (Figure 6). Unmutated growth of the wild strain at a $\mathrm{pH}$ value of 9 showed evidence of higher recovery at $14 \%$, and at $\mathrm{pH} 9.5$ of $16 \%$ in comparison to $11.3 \%$ recovery of gold for wild strains at $\mathrm{pH} 7$, which establishes the importance of the $\mathrm{pH}$ value in the bioleaching of gold (Figure 7). There was no gold recovery of unmutated the wild strains at a $\mathrm{pH}$ value of 10 , and gold bioleaching was attributable only to the production of cyanide which was produced by the bacteria. Natural adaptation tends to take longer, and random mutagenesis can be applied to support bacterial evolution by controlling the $\mathrm{pH}$ value as a pressure for selection.

\section{Conclusion}

The bioleaching of gold from EWM (Electronic Waste Material) was examined in this study by means of mutated and unmutated B. megaterium, as well as the effect of pretreatment of EWM. Pretreatment with nitric acid reduced the competition from other metals in the EWM for cyanide ion. The mutation was found to enhance the bioleaching process under alkaline conditions for dissolution of gold by greater $\mathrm{CN}^{-}$availability. Gold recovery was decreased by an increase in pulp density as a result of higher concentration of metals and due to the inhibitive impact on growth of bacteria and production of cyanide. Mutation of $B$. megaterium to grow at a $\mathrm{pH}$ value of 9.5 exhibited a higher biorecovery of gold relative to both the unmutated strain and to mutated strains at $\mathrm{pH}$ values of 9 and 10 .

\section{References}

[1] Gramatyka, P., Nowosielski, R., Sakiewicz, P., 2007. Recycling of waste electrical and electronic equipment. J. Achiev. Mater. Manuf. Eng. 20 (1-2), 535-538.

[2] Ramesh Babu, B., Parande, A.K., Ahmed Basha, C., 2007. Electrical and electronic waste: a global environmental problem. Waste Manag. Res. 25 (4), 307-318.

[3] Greenpeace, 2005. The E-Waste Problem, Vol. 2013. Accessed on 11 June, 2017

http://www.greenpeace.org/international/en/campaigns/toxics/elec tronics/ the-e-waste-problem/.

[4] ETBC, 2012. Electronics Take Back Coalition-Facts and Figures on E-Waste and Recycling. Accessed on 3 July, 2017. http://www.electronicstakeback.com/wp-content/uploads/ Facts_and_Figures_on_EWaste_and_Recycling.pdf.

[5] Cui, J., Zhang, L., 2008. Metallurgical recovery of metals from electronic waste: a review. J. Hazard. Mater. 158 (2-3), 228-256.

[6] Pham, V., Ting, Y.P., 2009. Gold bioleaching of electronic waste by cyanogenic bacteria and its enhancement with bio-oxidation. Adv. Mater. Res. 71, 661-664. 
[7] Korte, F., Spiteller, M., Coulston, F., 2000. The cyanide leaching gold recovery process is a nonsustainable technology with unacceptable impacts on ecosystems and humans: the disaster in Romania. Ecotoxicol. Environ. Saf. 46 (3), 241-245.

[8] Krebs, W., Brombacher, C., Bosshard, P.P., Bachofen, R., Brandl, H., 1997. Microbial recovery of metals from solids. FEMS Microbiol. Rev. 20 (3-4), 605-617.

[9] Bosecker, K., 1997. Bioleaching: metal solubilization by microorganisms. FEMS Microbiol. Rev. 20 (3-4), 591-604.

[10] Kita, Y., Nishikawa, H., Takemoto, T., 2006. Effects of cyanide and dissolved oxygen concentration on biological Au recovery. J. Biotechnol. 124 (3), 545-551.

[11] Faramarzi, M.A., Stagars, M., Pensini, E., Krebs, W., Brandl, H., 2004. Metal solubilization from metal-containing solid materials by cyanogenic Chromobacterium violaceum. J. Biotechnol. 113 (1), 321-326.

[12] Brandl, H., Lehmann, S., Faramarzi, M.A., Martinelli, D., 2008. Biomobilization of silver, gold, and platinum from solid waste materials by $\mathrm{HCN}$-forming microorganisms. Hydrometallurgy 94 (1), 14-17.

[13] Mecucci, A., Scott, K., 2002. Leaching and electrochemical recovery of copper, lead and tin from scrap printed circuit boards. J. Chem. Technol. Biotechnol. 77 (4), 449-457.

[14] Yamane, L.H., de Moraes, V.T., Espinosa, D.C.R., Tenório, J.A.S., 2011. Recycling of WEEE: characterization of spent printed circuit boards from mobile phones and computers. Waste Manage. (Oxford) 31 (12), 2553-2558.

[15] Brandl, H., Bosshard, R., Wegmann, M., 2001. Computermunching microbes: metal leaching from electronic scrap by bacteria and fungi. Hydrometallurgy 59 (2-3), 319-326.

[16] Mishra, D., Rhee, Y.H., 2010. Current research trends of microbiological leaching for metal recovery from industrial wastes. Curr. Res. Technol. Edu. Top. Appl. Microbiol. Microb. Biotechnol. 2, 1289-1292.

[17] Sum, E.Y.L., 1991. Recovery of metals from electronic scrap. JOM 43 (4), 53-61

[18] Kulandaisamy, S., Rethinaraj, J.P., Adaikkalam, P., Srinivasan, G., Raghavan, M., 2003. The aqueous recovery of gold from electronic scrap. JOM 55 (8), 35-38.
[19] Ilyas, S., Anwar, M.A., Niazi, S.B., Afzal Ghauri, M., 2007. Bioleaching of metals from electronic scrap by moderately thermophilic acidophilic bacteria. Hydrometallurgy 88 (1-4), 180-188.

[20] Liang, G., Mo, Y., Zhou, Q., 2010. Novel strategies of bioleaching metals from printed circuit boards (PCBs) in mixed cultivation of two acidophiles. Enzyme Microb. Technol. 47 (7), 322-326.

[21] Xiang, Y., Wu, P., Zhu, N., Zhang, T., Liu, W., Wu, J., Li, P., 2010. Bioleaching of copper from waste printed circuit boards by bacterial consortium enriched from acid mine drainage. J. Hazard. Mater. 184 (1-3), 812-818.

[22] Pant, D., Joshi, D., Upreti, M.K., Kotnala, R.K., 2011. Chemical and biological extraction of metals present in E waste: a hybrid technology. Waste Manage. (Oxford) 32 (5), 979-990.

[23] Tuncuk, A., Stazi, V., Akcil, A., Yazici, E.Y., Deveci, H., 2012. Aqueous metal recovery techniques from e-scrap: hydrometallurgy in recycling. Miner. Eng. 25 (1), 28-37.

[24] Hagelüken, C., Greinerstraat, A., 2005. Recycling of electronic scrap at Umicore's integrated metals smelter and refinery. pp. 307323.

[25] Mudder, T.I., Botz, M., Smith, A., 2001. Chemistry and Treatment of Cyanidation Wastes. Mining Journal Books, London, UK.

[26] Rajat, G., David, D., George, W.-C., 2005. Physical and chemical forms of cyanide. In: Cyanide in Water and Soil. CRC Press, pp. 15-23.

[27] Faramarzi, M.A., Brandl, H., 2006. Formation of water-soluble metal cyanide complexes from solid minerals by Pseudomonas plecoglossicida. FEMS Microbiol. Lett. 259 (1), 47-52.

[28] Chi, T.D., Lee, J., Pandey, B., Yoo, K., Jeong, J., 2011. Bioleaching of gold and copper from waste mobile phone PCBs by using a cyanogenic bacterium. Miner. Eng. 24 (11), 1219-1222.

[29] Lawson, E., Barkhuizen, M., Dew, D., 1999. Gold solubilisation by the cyanide producing bacteria Chromobacterium violaceum. Process Metall. 9, 239-246.

[30] Haque, K., 1992. The role of oxygen in cyanide leaching of gold ore. Can. min. metall. bull. 85 (963), 31-38. 